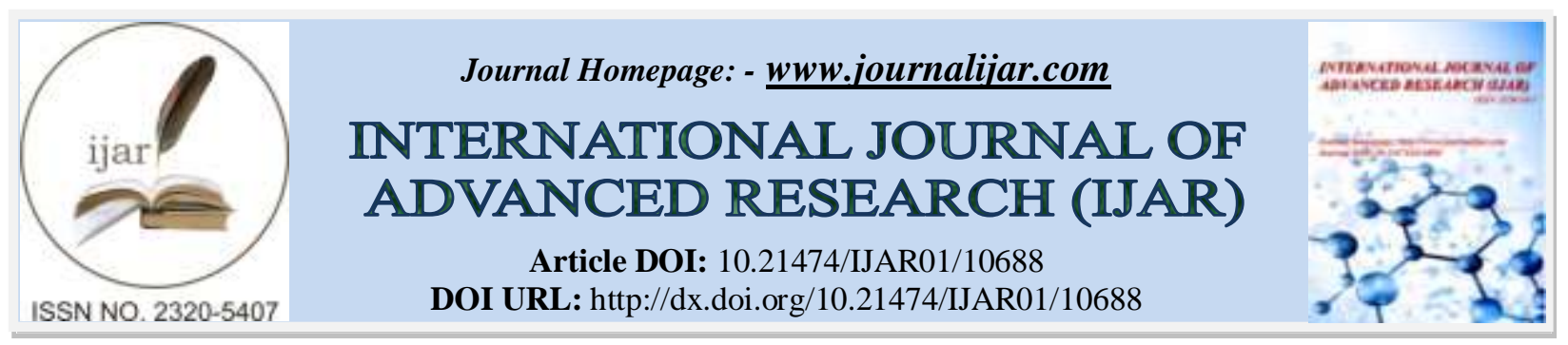

RESEARCH ARTICLE

\title{
RETROGRADE LASER CROSSING OF A LEFT SFA OCCLUSION WITH AN AMBIGUOUS PROXIMAL CAP
}

\section{Chakib Benajiba MD, Badre El Boussaadani MD, DiniaMohamed MD and Cherti Mohamed MD Cardiology B Department of CHU Ibn Sina, Rabat, Morocco.}

\begin{abstract}
Manuscript Info (n..........................

Manuscript History

Received: 17 January 2020

Final Accepted: 20 February 2020

Published: March 2020

Abstract

Endovascular treatment of femoralaretry occlusion is an increasingly common act, we have several mean sat our disposal to guide us during the treatment of occlusion of the femoral arteries, and with the advent of this new type of laser usedwithout a guidewire, the Dabra Laser represents an interesting alternative in our hands. Wedescribe the case of a 52-year-old man presented to ourclinicwithsevere intermittent claudication of the leftleg. A preoperative lower extremity arterial ultrasound indicated a long left superficial femoralartery (SFA) occlusion that was approximately $30 \mathrm{~cm}$ in length.We treated this patient with the new Laser technique DABRA retrogradely using the left anterior tibial artery with good final result.
\end{abstract}

Copy Right, IJAR, 2020,. All rights reserved.

\section{Introduction:-}

\section{Case Presentation:-}

A 52-year-old man presented to ourclinicwithsevere intermittent claudication of the leftleg (Rutherford class 3). The patient had a medicalhistory of smoking and diabetesmellitus. A preoperativelowerextremityarterialultrasoundindicated a long leftsuperficialfemoralartery (SFA) occlusion thatwasapproximately $30 \mathrm{~cm}$ in length.

\section{Treatment Options:}

Usingechocardiographic guidance, percutaneousaccesswasgained to the right commonfemoralartery, and a long, 6F, $45 \mathrm{~cm}$ Flexorintroducer (Cook Medical) wasused to achievecontralateralcrossing. A 0.018-inch Asahi Gaia PV wire (Asahi Intecc Co Ltd.) wasplaced in the proximal left SFA to attemptantegradecrossing of the occlusion. Angiographyconfirmed a long left SFA occlusion with an ambiguous proximal cap (Figure 1) but a good landing zone at the point of reconstitution (Figure 2). 


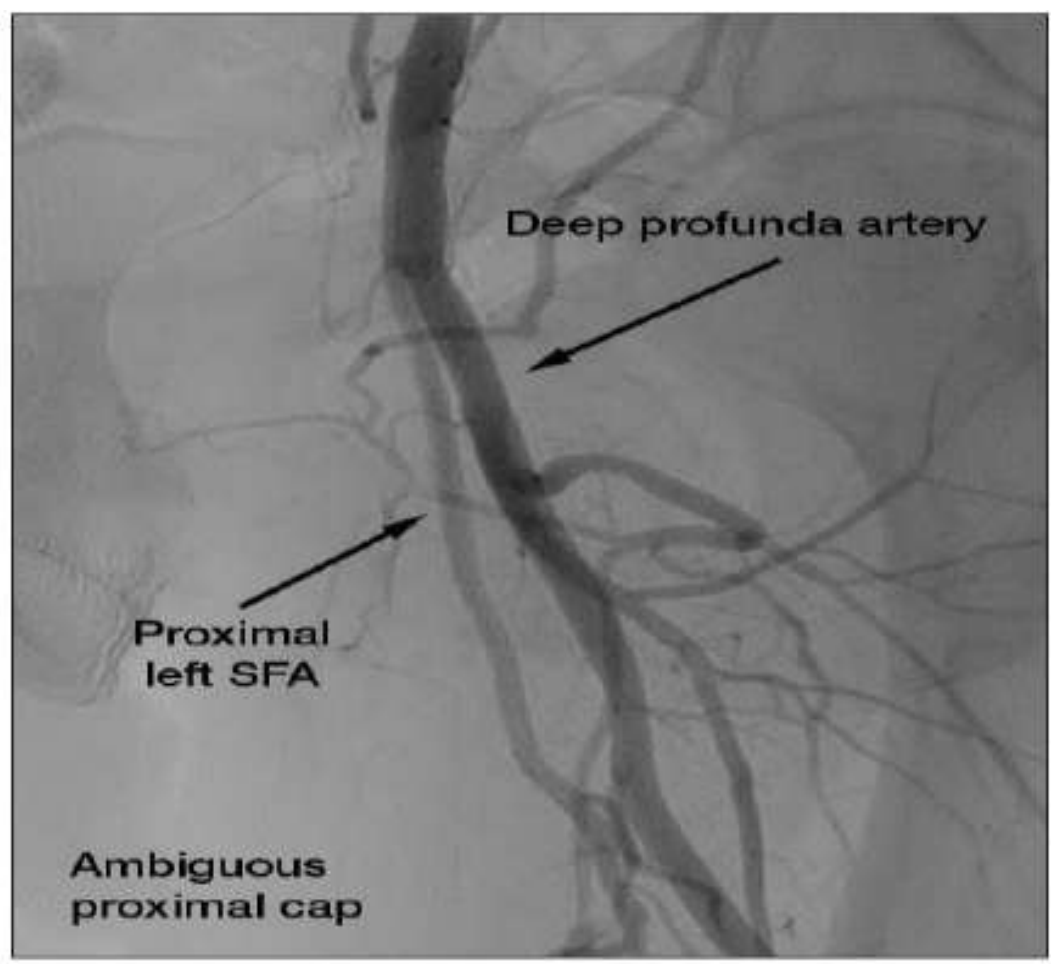

Figure 1:- Angiogramshowing the long left SFA occlusion with an ambiguous proximal cap.

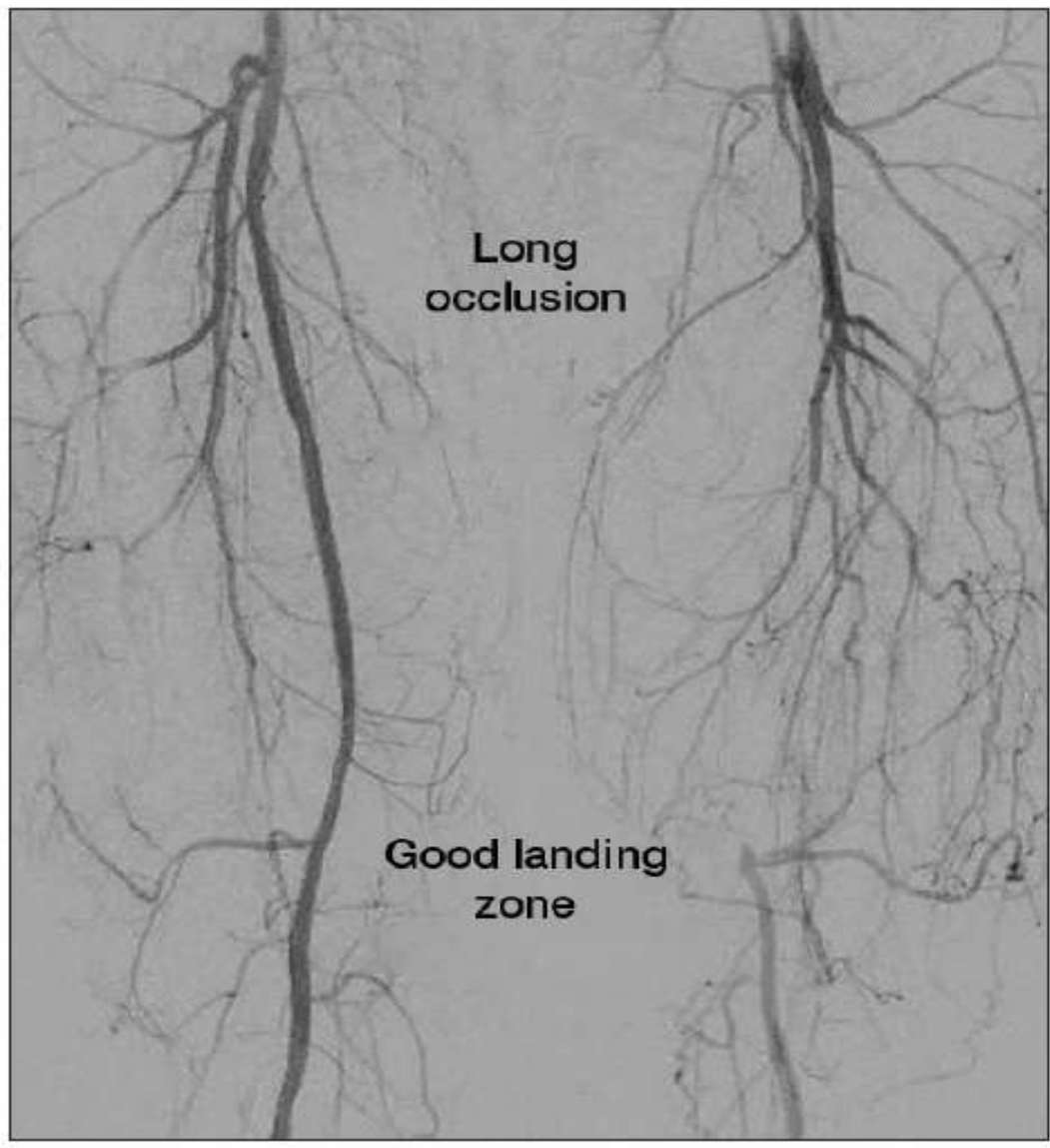

Figure 2: Angiogram of the left SFA showing a good landing zone at the point of reconstitution. 
The case presentedmany challenges given the ambiguous cap, the total occlusion, and the long lesionlength. Key treatmentconsiderationswere the best approach to access the SFA given the ambiguous cap and choosing a devicethatcouldsuccessfully cross and treat the long occlusion. Weopted to proceedwith a secondaryaccess point from the leftanterior tibial artery for retrogradecrossing of the proximal cap of the SFA. For treatment, wedecided to performatherectomyusing the DABRA Excimer Laser Atherectomy System (Ra MedicalSystems, Inc.) because of itsdemonstratedability to cross chronic total occlusions (CTOs) and safelytreat long and complexlesions of all plaque types.

\section{Course of treatment:}

The patient received a therapeutic dose of aspirin and clopidogrel the daybefore the procedure and 5,000 units of heparin the day of the procedure.

With the antegradewirestill in place, underroadmapping guidance and using a 21-gauge needlemicropuncture kit (Cook Medical), a retrogradepuncture of the leftanterior tibial arterywas made. A long, 5F, $45 \mathrm{~cm}$ braidedintroducerwasintroduced in a retrogradefashion over a 0.018 -inch guidewire. The wirewasthenremoved, and a 5F DABRA catheterwasintroduced and progressivelyadvanced in a retrogradefashion, from the distal to the proximal occlusion, until the proximal cap wasreached. An angiogramwasobtained, a slightadvancement and lasing of the DABRA was made underroadmapping control (Figure 3), and successfulretrogradecrossing of the proximal cap wasachieved (Figure 4).

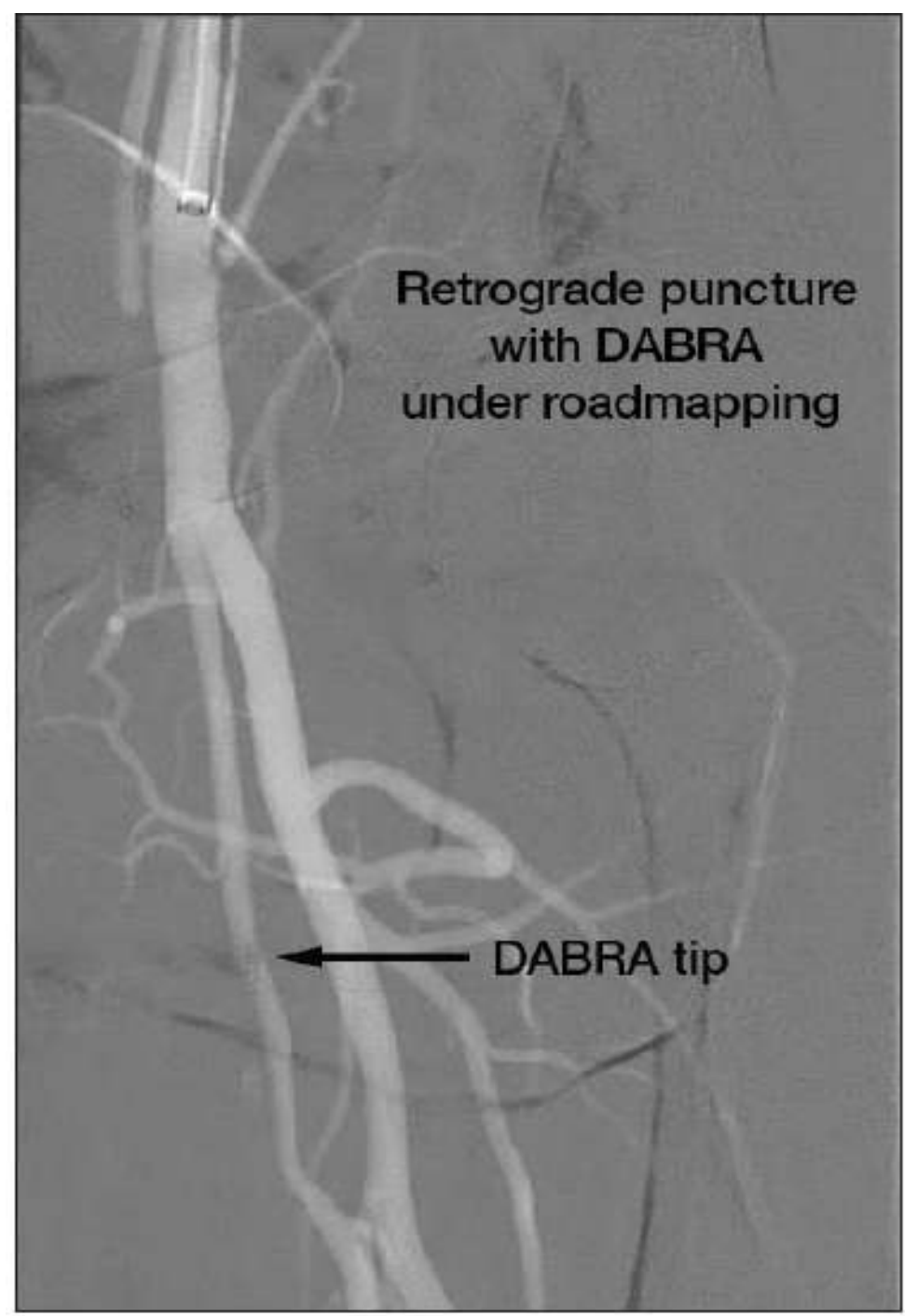

Figure 3:- Retrogradeadvancement and crossing of the proximal cap with the laser. 


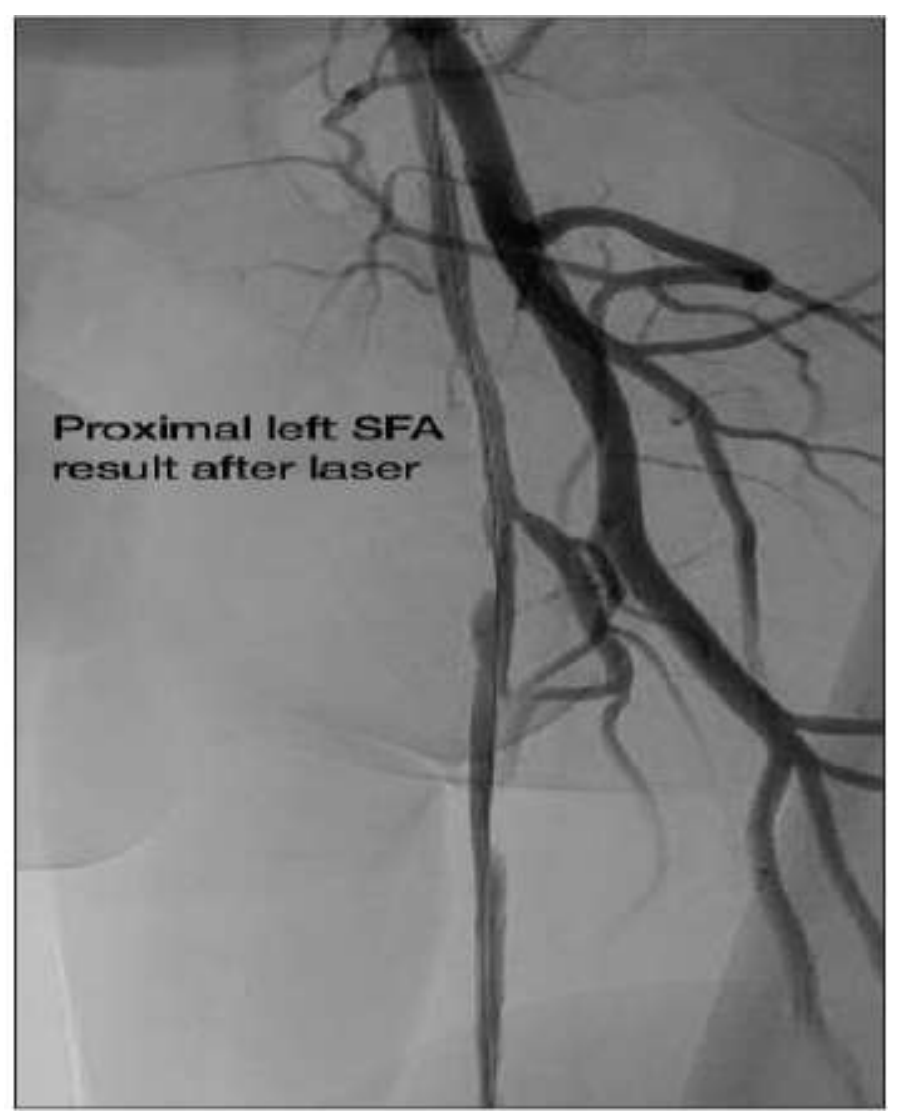

Figure 4:- Angiogram of the SFA aftersuccessfulretrograde laser crossing of the proximal cap.

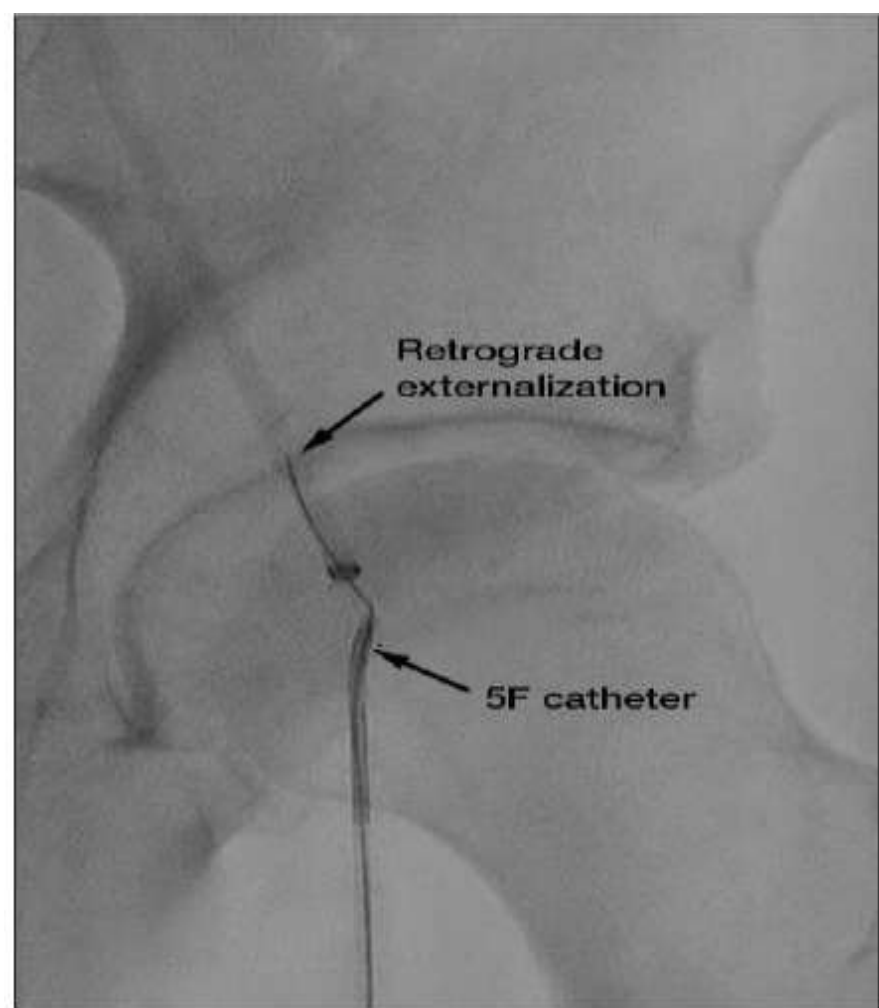

Figure 5:- Retrogradeexternalizationachievedwith a 0.018-inch guidewire and 5F Berensteincatheter. 
The smoothchannelcreated by the laser allowed us to easilyadvance a 0.018 -inch V-18 ControlWireguidewire (Boston Scientific Corporation) in a retrogradefashion. Next, retrogradeexternalizationwasachievedwith the 0.018inch guidewire and a 5F Berensteincatheter (Cordis, a Cardinal Healthcompany) (Figure 5), followed by a V-18 ControlWireguidewire exchange from an antegradeapproach, using a $135 \mathrm{~cm}$ CXI support catheter (Cook Medical). With a successfulwire exchange in place securingantegradeaccess, hemostasis of the leftanterior tibial arterywasperformedwith a combination of external compression and internalhemostasisusing a 3.5 X $30 \mathrm{~mm}$ Emerge balloon (Boston Scientific Corporation) inflated for 10 minutes. Finally, antegradetreatment of the SFA wasperformedusing a 5 X $100 \mathrm{~mm}$ Sterling balloon (Boston Scientific Corporation) inflated for 3 minutes, followed by two 5 X 150 mm Ranger drug-coatedballoons (Boston Scientific Corporation) inflated up to 3 minutes.

The dabra laser is a promising new toolwhichisusedwithout a guide for the treatment of arterial occlusions of the lowerlimbs, in our case it has been usedsuccessfully in the past.

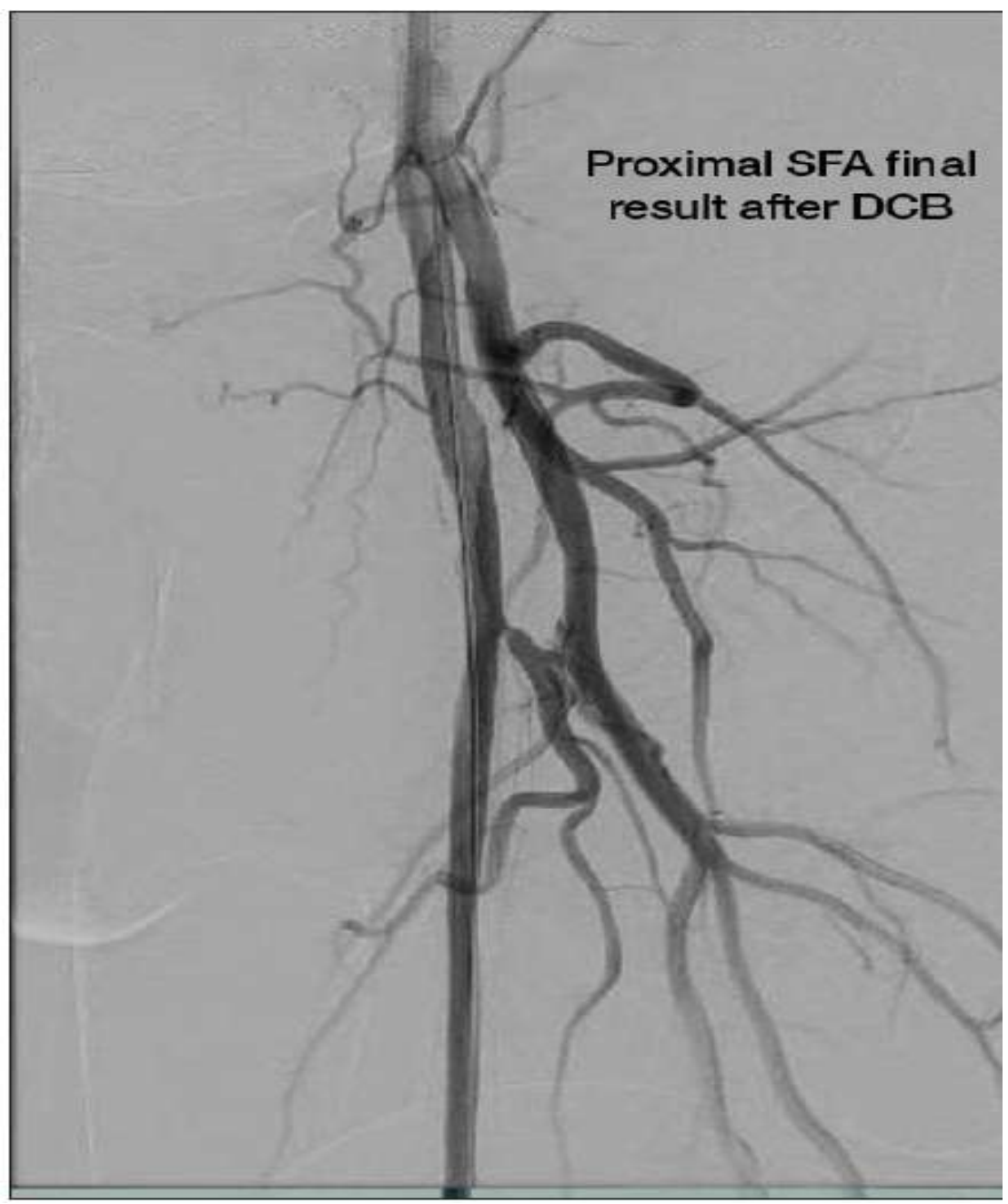

Figure 6:- Final resultwithresumed flow through the SFA.

\section{Results:-}

Postproceduralangiographyconfirmed an excellent resultwithresumed flow through the SFA (Figure 6). The total procedure time was 90 minutes, whichwasrelatively short given the multiple access points and overall case complexity.

\section{Discussion:-}

This case describes a successfulbidirectionalapproach for laser crossingthrough a long SFA occlusion. Use of a retrogradeapproachallowed for direct and rapidaccess to the SFA occlusion and successful laser crossing, avoiding 
the likelyincreasedprocedure and fluoroscopy times of an antegradeapproachgiven the ambiguous cap. Once the lesionwascrossed and debulkedwith laser atherectomy, an antegradeapproachwasutilized for follow-up treatment.

This case highlights the ease of use of the DABRA catheter, as thiswas one of our first cases with the device and itproved to bequite simple, evenwith the challenges of the case. It alsodemonstrates how the DABRA cathetercanbeeffectivelyused as a crosser and an atherectomydevice, becausewewerequickly able to cross the CTO and thenlase the entire $30 \mathrm{~cm}$ lesionwithjust the one device.

\section{Conclusion:-}

Endovasculartreatment of femoralaretryocclusion is an increasinglycommonact, we have severalmeansatourdisposal to guide us during the treatment of occlusion of the femoralarteries, and with the advent of this new type of laser usedwithout a guidewire, the Dabra Laser represents an interesting alternative in our hands. Studies on a largernumber of patients and over a long period are necessary to defineitstrue place in ourcurrent practice, as we know thisis the first case of retrogradeDabra Laser recrossing of SFA occlusion. 